\title{
Edítoríal.
}

\section{THE BRAIN AND MENTAL ILLNESS.}

A

RECENT joint meeting of the sections of Neurology and Psychiatry of the Royal Society of Medicine devoted to the 'Mental Symptoms of Cerebral Tumours' aroused the perennial question as to what cerebral localization has to teach in the domain of psychiatry. As might have been expected, the results of the discussion in this respect were negative rather than positive. The old hope, almost phrenological in its origins, that we should be able to map the brain into areas of cells subserving faculties and functions is doomed to disappointment. Even in those cases in which localized lesions are found to produce definite results it is becoming clear that the action of the lesion is rather to 'bomb a junction' than to ' destroy a factory' -in other words, that it is damage to association-fibres rather than to cell-bodies which produces such dramatic results.

These do not, however, drive us away from the conception of a strict correlation between brain and mind; recent work of von Economo and Jacob confirms and extends the earlier researches of Campbell, Watson, Shaw Bolton, and others, who endeavoured to show that it is to the microscopic rather than to the macroscopic structure of the brain that we must look for our pathological explanations. This is specially true in the domain of psychiatry, for in its province we are concerned with the function of the cortex rather than with that of other parts of the nervous system. The six laminæ of cells are well recognised, and it has been shown that the granular layers are concerned with afferent and the pyramidal cells with efferent function. Further, the postcentral areas known to be associated with sensory function are predominantly granular in structure, while the precentral areas known to be effector in function are predominantly pyramidal or agranular in structure.

Jacob has produced evidence to suggest that in those dementias showing personality changes-such as dementia præcox and general paralysis-the third layer pyramidal cells 
in certain areas bear the brunt of the destruction. The anatomical researches of Bolton, Berry and Tredgold and others on the mentally defective have demonstrated a deficiency in cortical neurones corresponding to the deficiency in wit; these deficiencies however are not areal in their distribution but are found to fall on the more superficial layers of cortical cells, which are the most recently acquired and distinguish the human cortex from that of the sub-human mammalia. Such discoveries explain the findings of Lashley and other investigators of animal psychology, who have found that in dealing with the psychological behaviour as opposed to the simpler motor and sensory responses of animals alterations in such behaviour, secondary to operative interference with the cortex, depend rather on the amount of cortex removed than on the locality of the lesion. In other words, higher receptor experience and effector behaviour depend on an intricate interconnexion of granular and pyramidal cells respectively. A small localized lesion of these cells has little effect on this higher experience or behaviour, but a large destruction will make a serious difference. If one of the main connectant bundles such as the corpus callosum or the inferior longitudinal bundle is interfered with, then much disturbance may result, just as the blocking of important trunk railway lines or the destruction of a nodal junction may disturb the traffic and communications over a wide area.

These researches into what are called cytoarchitectonics throw a considerable light upon the amentias and the dementias, but there is no evidence at present that they do so in respect of what are known as the purely functional psychoses. The study of the psychoneuroses, cyclothymias, schizophrenias and paranoias may be enlightened by further work on the distribution and arrangement of cortical neurones, but it must be remembered that the cell-body-the subject of these researches -is not the only important element in the composition of the nervous system. The synapse, although its existence is almost more negative than positive, since it is a 'non-structural space joining two nerve-cells,' is of the utmost significance. Sherrington has shown that delay in nerve-conduction occurs principally at the synapses; and we know that certain drugs inhibit or facilitate passage across thern, as the case may be.

It would seem a fair inference that modifications at the synapses in the form of facilitations and inhibitions are chemical in nature. It is further reasonable to suppose that such facilitation and inhibition constitute the physiological basis of repression, dissociation and the other 'mechanisms' of the 
functional psychoses. Much research has been carried out in these latter conditions a great deal of which is inconclusive and confusing, but one fact stands out, viz. that in many, if not in most, of these cases, there is some temporary or permanent modification of the biochemical balance of the body. Kretschmer and the Tübingen school have distinguished cycloid and schizoid types depending apparently on differences in endocrine, that is, in chemical balance. The school of modern psychology based on the various analytic groups emphasises how important emotional conflicts, strains and thwarting are in the production of mental illness ; but the chief, if not the only, bodily effect of such experiences is an upset in the endocrine and other chemical balance of the body, while their mental effects are inhibitions and relative facilitations resulting in dissociations, repressions and indirect symbolic manifestations.

It is possible, therefore, that in the organic psychoses we must look chiefly to the cell-bodies for our pathology and to pathological anatomy for our explanations, while in the functional psychoses we must look chiefly to the synapses for our pathology and to biochemistiy for our explanations, always remembering that biochemical changes may be produced by purely psychogenic and emotional influences.

It is well, however, to keep an open mind on all these counts when dealing with an individual case and to ask ourselves the following questions :

(1) How far is the patient an ament, i.e., possessed of an inherent anatomical defect.

(2) How far is he a dement, i.e., possessed of an acquired anatomical defect.

(3) How far is he of a special inherent chemical type such as is described by Kretschmer and others.

(4) How far has he acquired chemical disturbances which have upset the smooth working of his synapses.

(5) How far such chemical disturbances are due to extraneous causes such as bacterial invasion, fatigue products, etc.

(6) How far such chemical disturbances are caused by intrinsic endocrine changes themselves due to psychic emotional conflicts and experiences.

Too often at present the psychiatrist fastens on investigation of one of these problems to the exclusion of the rest, while in many patients most if not all of the factors named are operative. 
Psychiatry requires a great deal more knowledge before it can answer all such questions clearly, but if it is to acquire this knowledge its practitioners must cultivate a wide outlook which will embrace all lines of research in the interests of the cure of mental illness. 